\title{
Correction to: Shoulder Arthroplasty for Humeral Head Avascular Necrosis Is Associated with Increased Postoperative Complications
}

M. Tyrrell Burrus, MD • Jourdan M. Cancienne, MD • Jeffrey D. Boatright, MD, MS • Scott Yang, MD • Stephen F. Brockmeier, MD • Brian C. Werner, MD

Published online: 3 April 2018

(C) Hospital for Special Surgery 2018

Correction to: HSSJ (2018) 14:2-8

https://doi.org/10.1007/s11420-017-9562-8

Due to a metadata tagging error, the name of author $\mathrm{M}$.

Tyrrell Burrus was indexed incorrectly. M. Tyrrell is the given name and Burrus is the family name.

The online version of the original article can be found at https://doi.org/ 10.1007/s11420-017-9562-8

M. T. Burrus, MD

Department of Orthopaedic Surgery,

University of Michigan Health System,

24 Frank Lloyd Wright Drive,

Ann Arbor, MI 48106-0391, USA

J. M. Cancienne, MD $\cdot$ J. D. Boatright, MD, MS •

S. F. Brockmeier, MD $\cdot$ B. C. Werner, MD $(\triangle)$

Department of Orthopaedic Surgery,

University of Virginia Health System,

PO Box 800159 HSC, Charlottesville, VA 22908, USA

e-mail: bcw4x@virginia.edu

S. Yang, MD

Oregon Health and Science University,

700 S.W. Campus Drive, 7th floor,

Portland, OR 97239, USA 